\title{
Insulin resistance, intramyocellular lipid content, and plasma adiponectin in patients with type 1 diabetes
}

Gianluca Perseghin, Guido Lattuada, Massimo Danna, Lucia Piceni Sereni, Paola Maffi, Francesco De Cobelli, Alberto Battezzati, Antonio Secchi, Alessandro Del Maschio and Livio Luzi

Am J Physiol Endocrinol Metab 285:E1174-E1181, 2003. First published 21 August 2003;

doi: 10.1152/ajpendo.00279.2003

You might find this additional info useful...

This article cites 48 articles, 25 of which you can access for free at:

http://ajpendo.physiology.org/content/285/6/E1174.full\#ref-list-1

This article has been cited by 14 other HighWire-hosted articles:

http://ajpendo.physiology.org/content/285/6/E1174\#cited-by

Updated information and services including high resolution figures, can be found at:

http://ajpendo.physiology.org/content/285/6/E1174.full

Additional material and information about American Journal of Physiology - Endocrinology and Metabolism can be found at:

http://www.the-aps.org/publications/ajpendo

This information is current as of October 8, 2012.

American Journal of Physiology - Endocrinology and Metabolism publishes results of original studies about endocrine and metabolic systems on any level of organization. It is published 12 times a year (monthly) by the American Physiological Society, 9650 Rockville Pike, Bethesda MD 20814-3991. Copyright @ 2003 by American Physiological Society. ISSN: 0193-1849, ESSN: 1522-1555. Visit our website at http://www.the-aps.org/. 


\title{
Insulin resistance, intramyocellular lipid content, and plasma adiponectin in patients with type 1 diabetes
}

\author{
Gianluca Perseghin, ${ }^{1,5}$ Guido Lattuada, ${ }^{1}$ Massimo Danna, ${ }^{3,4,5}$ Lucia Piceni Sereni, ${ }^{1}$ \\ Paola Maffi, ${ }^{2}$ Francesco De Cobelli, ${ }^{4,5}$ Alberto Battezzati, ${ }^{1,6}$ Antonio Secchi, ${ }^{2}$ \\ Alessandro Del Maschio, ${ }^{4,5}$ and Livio Luzi ${ }^{1,5,6,7}$ \\ Sections of ${ }^{1}$ Nutrition/Metabolism and ${ }^{2}$ Organ Transplantation, Internal Medicine, ${ }^{3}$ Division of Nuclear \\ Medicine, ${ }^{4}$ Division of Diagnostic Radiology, and ${ }^{5}$ Unit of Clinical Spectroscopy, Università Vita e Salute San \\ Raffaele IRCCS H San Raffaele, 20132 Milan; and ${ }^{6}$ International Center for the Assessment of Nutritional \\ Status, and ${ }^{7}$ Faculty of Exercise Sciences, Università degli Studi di Milano, 20100 Milan, Italy
}

Submitted 19 June 2003; accepted in final form 19 August 2003

\begin{abstract}
Perseghin, Gianluca, Guido Lattuada, Massimo Danna, Lucia Piceni Sereni, Paola Maffi, Francesco De Cobelli, Alberto Battezzati, Antonio Secchi, Alessandro Del Maschio, and Livio Luzi. Insulin resistance, intramyocellular lipid content, and plasma adiponectin in patients with type 1 diabetes. Am J Physiol Endocrinol Metab 285: E1174-E1181, 2003. First published August 21, 2003;
\end{abstract} 10.1152/ajpendo.00279.2003.-Insulin resistance is a key pathogenic factor of type 2 diabetes (T2DM); in contrast, in type 1 diabetes (T1DM) it is considered a secondary alteration. Increased intramyocellular lipid (IMCL) content accumulation and reduced plasma adiponectin were suggested to be pathogenic events of insulin resistance in T2DM. This study was designed to assess whether IMCL content and plasma adiponectin were also associated with the severity of insulin resistance in T1DM. We studied 18 patients with T1DM, 7 older and overweight/obese patients with T2DM, and 15 nondiabetic, insulin-resistant offspring of T2DM parents (OFF) and 15 healthy individuals (NOR) as appropriate control groups matched for anthropometric features with T1DM patients by means of the euglycemic hyperinsulinemic clamp combined with the infusion of $\left[6,6-{ }^{2} \mathrm{H}_{2}\right]$ glucose and ${ }^{1} \mathrm{H}$ magnetic resonance spectroscopy of the calf muscles. T1DM and T2DM patients showed reduced insulin-stimulated glucose metabolic clearance rate (MCR: $5.1 \pm 0.6$ and $3.2 \pm 0.8$ $\left.\mathrm{ml} \cdot \mathrm{kg}^{-1} \cdot \mathrm{min}^{-1}\right)$ similar to OFF $\left(5.3 \pm 0.4 \mathrm{ml} \cdot \mathrm{kg}^{-1} \cdot \mathrm{min}^{-1}\right)$ compared with NOR $\left(8.5 \pm 0.5 \mathrm{ml} \cdot \mathrm{kg}^{-1} \cdot \mathrm{min}^{-1}, P<0.001\right)$. Soleus IMCL content was increased in T1DM (112 \pm 15 AU), T2DM (108 $\pm 10 \mathrm{AU})$ and OFF (82 $\pm 13 \mathrm{AU})$ compared with NOR (52 \pm 7 AU, $P<0.05)$ and the result was inversely proportional to the MCR $\left(R^{2}=0.27, P<0.001\right)$; an association between IMCL content and $\mathrm{Hb} \mathrm{A}_{1 \mathrm{c}}$ was found only in T1DM $\left(R^{2}=0.57, P<0.001\right)$. Fasting plasma adiponectin was reduced in T2DM ( $7 \pm 1 \mu \mathrm{g} / \mathrm{ml}, P=0.01)$ and OFF (11 \pm $1 \mu \mathrm{g} / \mathrm{ml}, P=0.03)$ but not in T1DM $(25 \pm 6 \mu \mathrm{g} / \mathrm{ml})$, whose plasma level was increased with respect to both OFF $(P=$ $0.03)$ and NOR $(16 \pm 2 \mu \mathrm{g} / \mathrm{ml}, P=0.05)$. In conclusion, in T1DM, T2DM, and OFF, IMCL content was associated with insulin resistance, demonstrating that IMCL accretion is a marker of insulin resistance common to both primary genetically determined and secondary metabolic (chronic hyperglycemia) alterations. The increased adiponectin levels in

Address for reprint requests and other correspondence: G. Perseghin, Internal Medicine, Section of Nutrition/Metabolism \& Unit of Clinical Spectroscopy, via Olgettina 60, 20132 Milan, Italy (E-mail: perseghin.gianluca@hsr.it). insulin-resistant patients with T1DM, in contrast to the reduced levels found in patients with T2DM and in OFF, demonstrated that the relationship of adiponectin to insulin resistance in humans is still unclear.

intramyocellular triglyceride content; leptin; magnetic resonance spectroscopy

INSULIN RESISTANCE typically characterizes type 2 diabetes (T2DM) and prediabetic states and is the prominent feature of the metabolic syndrome (8). Even if the primary metabolic defect of type 1 diabetes (T1DM) is considered to be insulin deficiency, a number of studies have suggested that a certain degree of insulin resistance is also present in patients with $\operatorname{T1DM}(9,10,11$, $26,31,47)$. An increased intramyocellular triglyceride (IMCL) content has been hypothesized to be the pathogenic event responsible for the development of insulin resistance in T2DM and in the insulin resistance syndrome (28). The noninvasive measurement of IMCL using ${ }^{1} \mathrm{H}$ magnetic resonance spectroscopy (MRS) at 1.5 Tesla field strength $(6,42)$, which allows one to measure separately lipids in fat cells and lipids located in the cytoplasm of muscle cells, demonstrated a strong inverse relationship between insulin sensitivity and IMCL content in normal humans (25), individuals with increased risk of developing T2DM (14, 23, 27, 35), and patients with obesity and T2DM (41). For all this evidence, the concept of IMCL storage as a local marker of whole body insulin resistance has been recognized (39).

Adiponectin, a plasma protein exclusively produced by the adipose tissue, has recently been suggested to be an insulin-sensitizing agent involved in the pathogenesis of insulin resistance $(1,5,20,44,46)$. Whether an inappropriate accretion of the IMCL content and reduced circulating adiponectin levels might also be involved in the pathogenesis of insulin resistance in patients with T1DM is unknown. This study was de-

The costs of publication of this article were defrayed in part by the payment of page charges. The article must therefore be hereby marked "advertisement" in accordance with 18 U.S.C. Section 1734 solely to indicate this fact. 
signed to assess the relationships of insulin resistance to IMCL content and plasma adiponectin levels in patients with T1DM. T1DM patients had to be compared with T2DM patients, but because the anthropometric features of these two groups of diabetic individuals were completely different, a more appropriate comparison was also made with tightly matched insulin-resistant first-degree offspring of parents with T2DM (OFF), who are known to be characterized by alterations of insulin action similar to those of their parents $(17,32,35)$, and with normal healthy (NOR) subjects.

\section{METHODS}

\section{Subjects}

Eighteen patients with T1DM and seven patients with recently diagnosed T2DM recruited at the outpatient service of the Diabetes Unit of the Istituto Scientifico H San Raffaele, and 30 healthy individuals with (OFF) or without (NOR) first-degree relatives with T2DM recruited at the Center of Nutrition/Metabolism, participated in the study. Among the 18 T1DM patients, five had proliferative retinopathy, four had nonproliferative retinopathy, and three had sensorymotor nuropathy. None of the patients with T2DM had signs of retinopathy, neuropathy, or nephropathy, but they were obviously older and fatter than the patients with T1DM. Individuals in the control groups ( $\mathrm{OFF}$ and $\mathrm{NOR}$ ) were selected to be tightly comparable to T1DM for anthropometric features and lifestyle habits. Habitual physical activity was assessed using a questionnaire (2). Body weights were stable for $\geq 6-12$ mo. The three women with T2DM were in menopause. Two women of those with T1DM were taking oral steroidal contraception (OSC), and because of the possible effects of OSC on insulin sensitivity and IMCL content (36) two of the women in the OFF and NOR groups were selected because they were in OSC treatment. The anthropometric characteristics of the subjects are summarized in Table 1. All subjects were in good health as assessed by medical history, physical examination, hematological analysis, and urinalysis. Informed consent was obtained from all subjects after explanation of the purposes, nature, and potential risks of the study. The protocol was approved by the Ethics Committee of the Istituto Scientifico H San Raffaele.

\section{Experimental Protocol}

Subjects were instructed to consume an isocaloric diet and to abstain from exercise activity for $3 \mathrm{wk}$ before the studies. Women were studied between days 3 and 8 of the menstrual cycle. Subjects were studied by means of the euglycemic hyperinsulinemic clamp to assess whole body insulin sensitivity after a 10-h overnight fast and during the insulin clamp. Within 2-3 days, they were studied by means of ${ }^{1} \mathrm{H}$ MRS to assess IMCL content. The MRS session was performed in the Division of Diagnostic Radiology of the Istituto Scientifico H San Raffaele between 0700 and 0900 after a 10-h overnight fast.

Euglycemic hyperinsulinemic clamp. Patients with T1DM were instructed to undergo the usual therapeutic regimen the day before the studies and to abstain from taking any subcutaneous insulin in the morning of the clamp and MRS studies. Patients with T2DM were not taking any drug and were only on a diet treatment. Subjects were admitted to the Metabolic Unit of the Division of Internal Medicine I of the Istituto Scientifico H San Raffaele the night before the clamp study. During the night, when capillary glucose concentration exceeded $11 \mathrm{mmol} / \mathrm{l}$, an exogenous insulin infusion $(0.1$ $\mathrm{mU} \cdot \mathrm{kg}^{-1} \cdot \mathrm{min}^{-1}$ ) was started. Nondiabetic patients were admitted at 0700 after a 10 -h overnight fast. A Teflon catheter was inserted into an antecubital vein for infusions, and an additional one was inserted retrogradely into a wrist vein for blood sampling. The hand was kept in a heated box throughout the experiment to allow sampling of arterialized venous blood. A bolus of $5 \mathrm{mg} / \mathrm{kg}$ body wt of $\left[6,6-{ }^{2} \mathrm{H}_{2}\right]$ glucose was administered to the OFF and NOR groups; the bolus administered to T1DM patients was adjusted, as previously described (19), according to the fasting plasma glucose con-

Table 1. Anthropometric and laboratory characteristics of the study groups

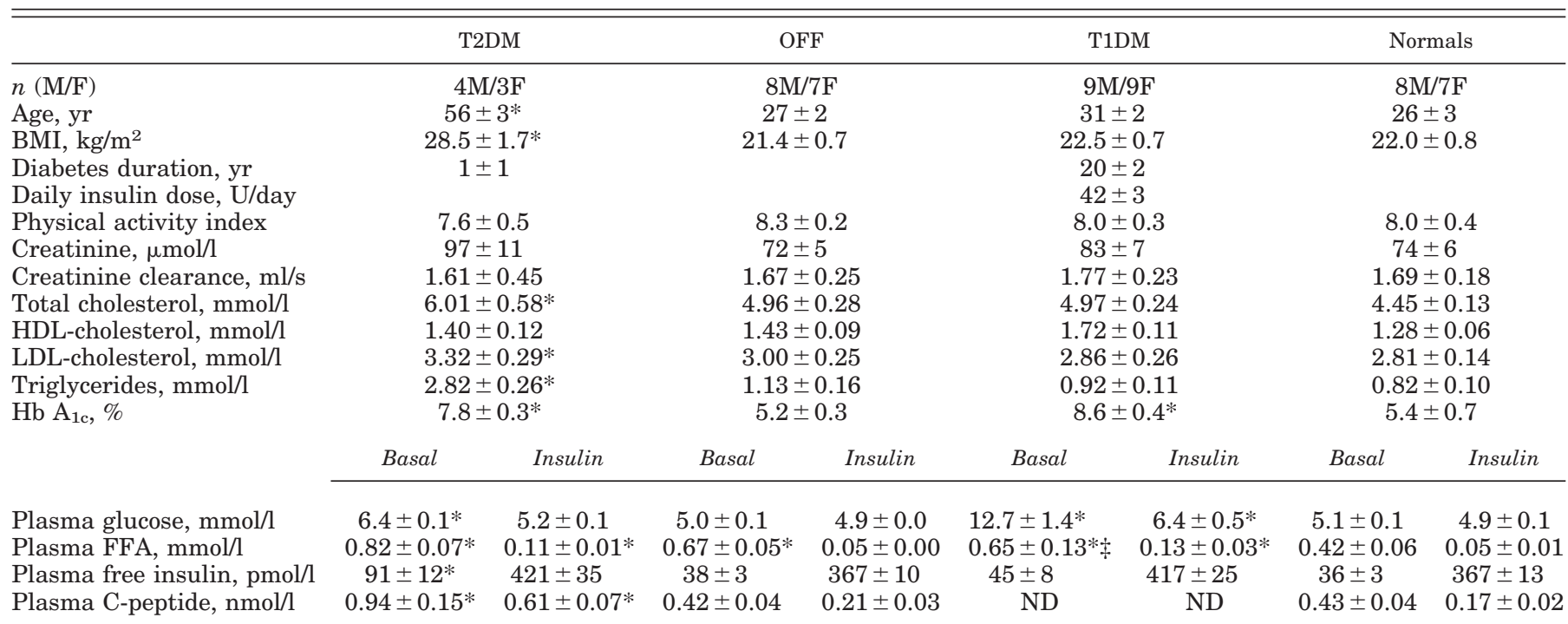

Values are means \pm SE. BMI, body mass index; FFA, free fatty acids; T2DM, patients with type 2 diabetes; OFF, first-degree relatives of T2DM; T1DM, patients with type 1 diabetes. LDL-cholesterol was calculated using Friedewald's formula. Basal indicates the fasting state; Insulin indicates the last $30 \mathrm{~min}$ of the insulin clamp; ND, $<0.015 \mathrm{nmol} / \mathrm{l}$. $* P<0.01 \mathrm{vs}$. Normals. $\$$ Morning of the magnetic resonance spectroscopy study, without overnight insulin infusion, fasting plasma venous FFA was $0.93 \pm 0.11 \mathrm{mmol} / \mathrm{l}(P<0.001 \mathrm{vs}$. Normals $)$. 
centration. Immediately after administration of the bolus, a continuous infusion $\left(0.05 \mathrm{mg} \cdot \mathrm{kg}\right.$ body $\left.\mathrm{wt}^{-1} \cdot \mathrm{min}^{-1}\right)$ of $[6,6-$ ${ }^{2} \mathrm{H}_{2}$ ] glucose (MassTrace, Woburn, MA) was started. Blood samples for postabsorptive plasma glucose, total cholesterol, HDL-cholesterol, triglycerides, free fatty acids, insulin, Cpeptide, tumor necrosis factor- $\alpha$ receptor-2 ( $\alpha$-TNFR2), leptin, and adiponectin were performed in duplicate in the postabsorptive condition. After a 150-min tracer equilibration period, a euglycemic hyperinsulinemic clamp was performed as previously described $(35,36)$. Insulin was infused at $40 \mathrm{mU} \cdot \mathrm{m}^{-2} \cdot \mathrm{min}^{-1}$ to reach a plasma insulin concentration of $\sim 350 \mathrm{pmol} / \mathrm{l}$, and plasma glucose concentration was kept at $\sim 5 \mathrm{mmol} / \mathrm{l}$ for an additional 150 min by means of a variable infusion of $20 \%$ dextrose. When fasting hyperglycemia was present in T1DM and T2DM patients, the plasma glucose concentration was allowed to drop to the euglycemic level, and thereafter the attempt was made to maintain a plasma glucose concentration of $5 \mathrm{mmol} / \mathrm{l}$ as in the normoglycemic individuals. Blood samples for plasma hormones, substrates, and tracer enrichment were drawn every $15 \mathrm{~min}$ throughout the study.

${ }^{1} H$ MRS. ${ }^{1} \mathrm{H}$ MRS was performed on a GE Signa 1.5 Tesla scanner (General Electric Medical Systems, Milwaukee, WI) using a conventional linear extremity coil as previously described $(35,36)$. Briefly, high resolution $\mathrm{T}_{1^{-}}$ weighted images of the right calf were obtained before the spectroscopic acquisitions to localize the voxel of interest for the ${ }^{1} \mathrm{H}$ spectroscopy study. Voxel shimming was executed to optimize the homogeneity of the magnetic field within the specific volume of interest. Two ${ }^{1} \mathrm{H}$ spectra were collected from a $15 \times 15 \times 15-\mathrm{mm}$ volume within the soleus and tibialis anterior muscles, respectively. A PRESS pulse sequence $(\mathrm{TR}=2,000 \mathrm{~ms}$ and $\mathrm{TE}=60 \mathrm{~ms}$ ) was used, and 128 averages were accumulated for each spectrum, with a final acquisition time of $4.5 \mathrm{~min}$. The water signal was suppressed during the acquisition, as it would have dominated the other metabolite's peak signals of interest. A third ${ }^{1} \mathrm{H}$ spectrum of a triglyceride solution inside a glass sphere, positioned within the extremity coil next to the calf, was also obtained during the same session to acquire an external standard in the same conditions as the subject's spectra. Postprocessing of the data, executed with the Sage/IDL software (General Electric Medical Systems), consisted of high-pass filtering, spectral apodization, zero filling, Fourier transformation, and phasing of the spectra. The integral of the area under the peak was calculated using a Marquardt fitting with Lorentzian functions of the peaks of interest. The integral of the methylene signal $\left(-\mathrm{CH}_{2}\right)$ at $1.35 \mathrm{ppm}$ was used to calculate IMCL content expressed in arbitrary units (AU) as a ratio with the integral of the peak of the external standard times 1,000.

\section{Analytical Procedures}

Plasma glucose was measured with a Beckman glucose analyzer (35). Plasma free fatty acids and plasma total cholesterol, HDL-cholesterol, and triglycerides were measured as previously described (35). LDL-cholesterol was calculated using the Friedewald formula. Plasma free insulin was measured with microparticle enzyme immunoassay technology (36) with no cross-reactions with proinsulin, C-peptide, and glucagon (IMx Insulin assay; Abbott Laboratories, Rome, Italy), and C-peptide was measured by RIA with a double antibody (36). Plasma leptin concentrations were determined, as previously described (36), by RIA with a human kit (Linco Research, St. Charles, MO) following the manufacturer's assay protocol [intra- and interassay coefficients of vari- ation $(\mathrm{CV})<5$ and $<10 \%$, respectively]. $\alpha$-TNFR2 was measured with an enzyme immunoassay (Immunotech; Beckman Coulter, Marseille, France) following the manufacturer's recommendations (intra- and interassay $\mathrm{CV}<3 \%$ and $5 \%$, respectively). Plasma adiponectin was measured using a commercially available RIA kit (catalog no. HADP-61HK; Linco Research) (21). The intra- and interassay CV for adiponectin were $4 \pm 1$ and $14 \pm 3 \%$, respectively. The titers of the immunologic markers of T1DM (anti-GAD, -ICA, and -IA2 antibodies) were measured as previously described (33). The $\left[{ }^{2} \mathrm{H}_{2}\right]$ glucose enrichment was measured by GC-MS as previously described (3).

\section{Calculations}

Glucose kinetics were calculated using Steele's equations for the nonsteady state (40). Steady state of plasma dideuterated glucose enrichments was reached in the study groups during both the end of the equilibration period and the last 30 min of the insulin clamp. Endogenous glucose production was calculated by subtracting the glucose infusion rate from the rate of glucose appearance measured with the isotope tracer technique. Total body glucose uptake was determined during the clamp by adding the rate of residual endogenous glucose production to the rate of glucose disappearance. The metabolic clearance rate (MCR) was calculated to normalize the glucose turnover rate to the plasma glucose concentration.

\section{Statistical Analysis}

All data are presented as means \pm SE. Comparisons among groups were performed using the analysis of variance and Tukey's post hoc testing when appropriate. Simple regression analysis was performed to assess relationships between variables.

\section{RESULTS}

\section{Anthropometric and Laboratory Characteristics of Study Groups}

Anthropometric parameters of the study subjects are summarized in Table 1. T1DM, OFF, and NOR subjects were tightly matched for age, sex, body mass index, and physical activity index; in contrast, T2DM subjects were older and fatter.

\section{Glucose Metabolism in Postabsorptive State and During Insulin Clamp}

Postabsorptive plasma glucose levels (Table 1) and endogenous glucose production rates were increased in T1DM $\left(4.15 \pm 0.34 \mathrm{mg} \cdot \mathrm{kg}^{-1} \cdot \mathrm{min}^{-1} ; P<0.001\right)$ compared with T2DM, OFF, and NOR groups (2.59 \pm 0.08 , $2.19 \pm 0.06$, and $2.39 \pm 0.11 \mathrm{mg} \cdot \mathrm{kg}^{-1} \cdot \mathrm{min}^{-1}$, respectively). During the insulin clamp, plasma glucose concentration was maintained at the fasting level in T2DM, OFF, and NOR subjects, whereas in T1DM patients it was allowed to drop to euglycemic levels, and thereafter it was clamped at a slightly higher level than in the OFF and NOR groups (Table $1 ; P=0.05$ ). During the clamp, T1DM patients showed a certain degree of insulin resistance with respect to the suppression of the endogenous glucose production $(69 \pm 5$ vs. $79 \pm 11,86 \pm 4$, and $88 \pm 8 \%$ in T1DM vs. T2DM, $\mathrm{OFF}$, and NOR, respectively; $P=0.05$ ), even if it must 

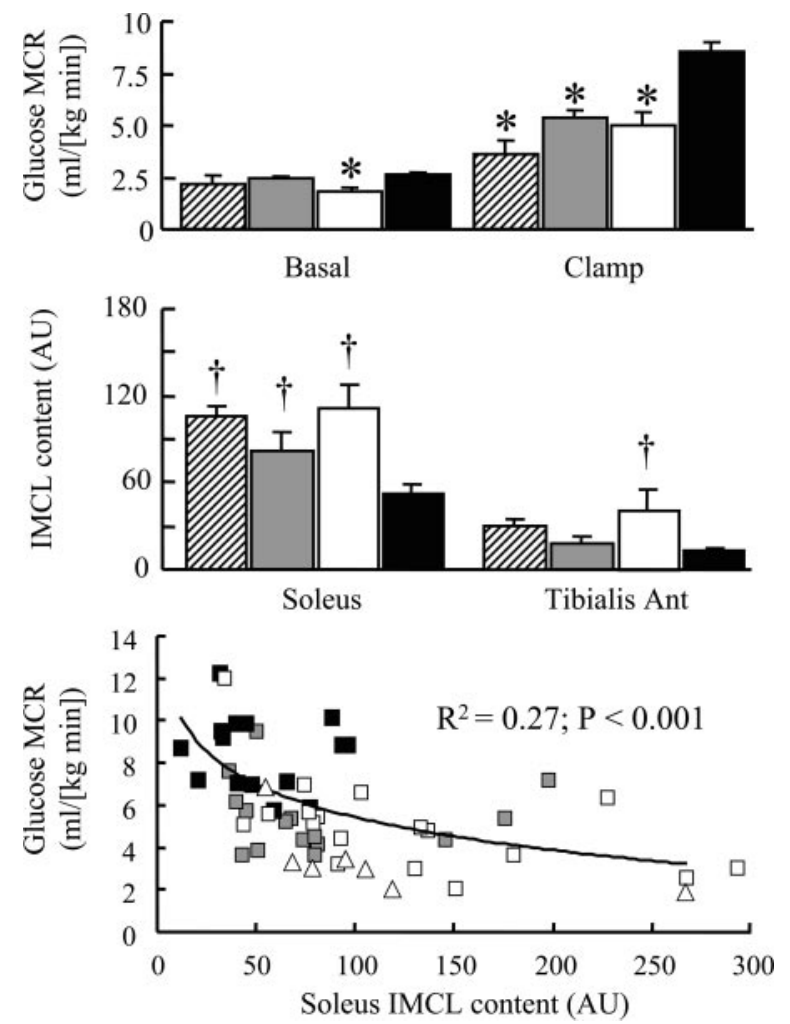

Fig. 1. Insulin resistance and intramyocellular lipid (IMCL) content. Top: glucose metabolic clearance rate (MCR) was shown to be reduced in both fasting and insulin-stimulated states in type 1 diabetes (T1DM) and in the insulin-stimulated state in T2DM and in insulinresistant T2DM offspring (OFF) compared with healthy individuals without T2DM (normal, NOR). Middle: IMCL content was increased in the soleus muscle of T1DM, T2DM, and OFF compared with NOR, whereas a significant IMCL content in the tibialis anterior was found only in T1DM. Bottom: summary of the relationship between MCR and soleus IMCL content. This relationship was best fitted with a logarithmic function $\left(R^{2}=0.27, P<0.001\right)$. Hatched bars (top and middle) and open triangles (bottom), T2DM; gray bars and squares, OFF; open bars and squares, T1DM; filled bars and squares, NOR. $* P<0.001$ vs. NOR; $\dagger P<0.05$ vs. NOR.

be stated that the insulin dose used in the present experimental protocol $\left(40 \mathrm{mU} \cdot \mathrm{m}^{-2} \cdot \mathrm{min}^{-1}\right)$ was probably too high to detect more subtle differences at the level of the endogenous glucose production. Also, the insulin-stimulated glucose metabolism was impaired in T1DM $\left(5.31 \pm 0.46 \mathrm{mg} \cdot \mathrm{kg}^{-1} \cdot \mathrm{min}^{-1}, P<0.01\right)$ as well as in T2DM $\left(3.19 \pm 0.78 \mathrm{mg} \cdot \mathrm{kg}^{-1} \cdot \mathrm{min}^{-1}, P<\right.$ $0.01)$ and OFF subjects $\left(4.76 \pm 0.40 \mathrm{mg} \cdot \mathrm{kg}^{-1} \cdot \mathrm{min}^{-1}\right.$, $P<0.01)$ compared with the NOR group $(7.54 \pm 0.37$ $\left.\mathrm{mg} \cdot \mathrm{kg}^{-1} \cdot \mathrm{min}^{-1}\right)$. Because fasting and clamp plasma glucose levels were slightly but significantly higher in T1DM and T2DM patients compared with the other groups, estimates of insulin-stimulated glucose metabolic rates had to be corrected for the circulating glucose levels. The glucose MCR was therefore calculated and found to be similarly reduced in the T1DM, T2DM, and OFF groups compared with the NOR group (5.1 \pm $0.6,3.51 \pm 1.0$, and $5.3 \pm 0.4 \mathrm{ml} \cdot \mathrm{kg}^{-1} \cdot \mathrm{min}^{-1}$, respectively, vs. $8.5 \pm 0.5 \mathrm{ml} \cdot \mathrm{kg}^{-1} \cdot \mathrm{min}^{-1}, P<0.001$; Fig. 1 , top).

\section{IMCL Content}

${ }^{1} \mathrm{H}$ MRS of the calf muscle showed that IMCL content was increased in T1DM $(112 \pm 15 \mathrm{AU}), \mathrm{T} 2 \mathrm{DM}$ $(108 \pm 10 \mathrm{AU})$, and OFF ( $82 \pm 13 \mathrm{AU})$ compared with NOR subjects (52 \pm 7 AU, $P<0.05$; Fig. 1 , middle) in the soleus muscle, whereas in the tibialis anterior only T1DM patients showed a significant increment of IMCL $(40 \pm 15$ AU vs. $23 \pm 3,19 \pm 5$, and $13 \pm 2 \mathrm{AU}$, $P=0.05$; Fig. 1, middle).

\section{Plasma Adiponectin, Leptin and Soluble $\alpha$-TNFR2 Concentrations}

Plasma adiponectin levels were reduced in T2DM ( $7 \pm 1 \mu \mathrm{g} / \mathrm{ml}, P=0.01$ vs. NOR) and OFF subjects (11 $\pm 1 \mu \mathrm{g} / \mathrm{ml}, P=0.03$ vs. NOR) but not in T1DM patients $(25 \pm 6 \mu \mathrm{g} / \mathrm{ml})$, whose plasma level was increased compared with the T2DM $(P=0.01), \operatorname{OFF}(P=$ 0.03 ), and NOR groups ( $16 \pm 2 \mu \mathrm{g} / \mathrm{ml}, P=0.05$; Fig. 2 ). At the end of the clamp study, plasma adiponectin concentration showed a nonsignificant decrement of $5 \pm 5,6 \pm 9,7 \pm 10$, and $6 \pm 9 \%$ in the T2DM, OFF, T1DM, and NOR subjects, respectively. The lack of a significant decrement is in contrast to the work by $\mathrm{Yu}$ et al. (48), but this discrepancy is likely due to the different duration (300-min vs. 150 -min clamps in the present study) and to the different insulin dose (80 vs. $40 \mathrm{mU} \cdot \mathrm{m}^{-2} \cdot \mathrm{min}^{-1}$ in the present study) designed for these clamp studies. Fasting plasma leptin concentrations $(5.0 \pm 1.3,6.2 \pm 1.4$, and $4.6 \pm 0.7 \mathrm{ng} / \mathrm{ml}, P=$ 0.77 ) were similar in the T1DM, OFF, and NOR groups, respectively, and increased in T2DM patients $(10.6 \pm 2.0 \mathrm{ng} / \mathrm{ml})$ according to the increased body mass index. $\alpha$-TNFR2 concentrations $(1.4 \pm 0.1,1.5 \pm 0.1$, $1.4 \pm 0.1$, and $1.3 \pm 0.1 \mathrm{ng} / \mathrm{ml}, P=0.44$ ) were not different in the T1DM, T2DM, OFF, and NOR groups, respectively.

\section{Effects of Metabolic Control}

To test whether the above-described metabolic and endocrine parameters observed in patients with T1DM may be explained by a different metabolic control, analysis of data was performed segregating and comparing the patients in good $\left(n=5 ; \mathrm{Hb} \mathrm{A}_{1 \mathrm{c}}<7.5 \%\right)$ and poor $\left(n=13 ; \mathrm{Hb} \mathrm{A} \mathrm{A}_{1 \mathrm{c}}>7.6 \%\right)$ metabolic control (Table

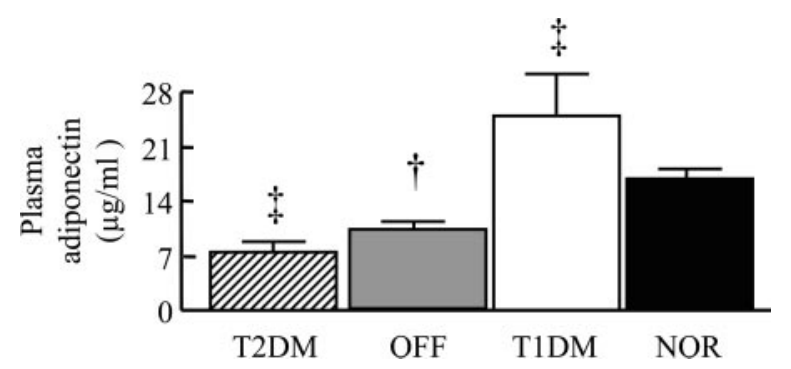

Fig. 2. Fasting plasma adiponectin concentration was reduced in T2DM and OFF compared with NOR. In contrast, fasting plasma adiponectin concentration was increased in T1DM patients compared with T2DM, OFF, and NOR. Hatched column, T2DM; gray bar, OFF; open bar, T1DM; filled bar, NOR. $\ddagger P<0.03$ vs. NOR; $\uparrow P<$ 0.05 vs. NOR. 
Table 2. Metabolic features of T1DM patients in good $\left(\mathrm{Hb} A_{1 c}<7.5 \%\right)$ and poor ( $\left.\mathrm{Hb} A_{1 c}>7.6 \%\right)$ metabolic control

\begin{tabular}{|c|c|c|}
\hline & Good Control & Poor Control \\
\hline$n(\mathrm{M} / \mathrm{F})$ & $2 \mathrm{M} / 3 \mathrm{~F}$ & $7 \mathrm{M} / 6 \mathrm{~F}$ \\
\hline Age, yr & $28 \pm 4$ & $32 \pm 2$ \\
\hline BMI, kg/m² & $21.0 \pm 0.8$ & $22.9 \pm 0.9$ \\
\hline $\mathrm{Hb} \mathrm{A} A_{1 \mathrm{c}}, \%$ & $6.7 \pm 0.2$ & $9.3 \pm 0.4^{*}$ \\
\hline Glucose MCR, $\mathrm{mg} \cdot \mathrm{kg}^{-1} \cdot \mathrm{min}^{-1}$ & $6.9 \pm 1.33$ & $4.65 \pm 0.40$ \\
\hline Soleus IMCL content, AU & $71 \pm 7$ & $148 \pm 23 \dagger$ \\
\hline Adiponectin, $\mu \mathrm{g} / \mathrm{ml}$ & $23 \pm 3$ & $29 \pm 6$ \\
\hline Plasma FFA, mmol/l & $0.69 \pm 0.23$ & $0.98 \pm 0.22$ \\
\hline
\end{tabular}

Values are means \pm SE. MCR, metabolic clearance rate; IMCL, intramyocellular lipid. ${ }^{*} P<0.01$ vs. Good Control; $\dagger P<0.05$ vs. Good Control.

2). Those in good metabolic control showed a higher insulin-stimulated glucose MCR $(P<0.05)$ in association with lower soleus IMCL content $(P<0.05)$. In contrast, no effect was observed on the plasma adiponectin concentration.

\section{Regression Analysis}

The glucose MCR was inversely associated with the IMCL soleus content (Fig. 1, bottom, $R^{2}=0.27, P<$ $0.001)$ and plasma free fatty acid levels $\left(R^{2}=0.25, P<\right.$ 0.01 ), and these relationships were best fitted with a logarithmic curve. The associations of glucose MCR with the soleus IMCL content and plasma free fatty acids were maintained separately in the study groups of normal-weight individuals (OFF, T1DM, NOR) but were not in the patients with T2DM $\left(R^{2}=0.15, P=\right.$ $0.23)$. The association of $\mathrm{Hb} \mathrm{A}_{1 \mathrm{c}}$ with glucose $\mathrm{MCR}$ $\left(R^{2}=0.27, P<0.04\right)$ and both soleus (Fig. $3: R^{2}=0.57$, $P<0.001)$ and tibialis anterior $\left(R^{2}=0.37, P<0.02\right)$ IMCL content was found only in the group of patients with T1DM. No associations were found between parameters of insulin sensitivity and the titers of the immunologic markers of T1DM (anti-GAD, -ICA, and -IA2 antibodies). No association was found between adiponectin and the glucose MCR or the disappearance rate separately in each study group; a significant relationship was also lacking when individual data were plotted all together. When data regarding the T1DM patients were excluded and the analysis was limited to T2DM, OFF, and NOR subjects, a significant relationship was close to being reached $\left(R^{2}=0.21 ; P=0.07\right)$. No association was found between adiponectin and endogenous glucose production in the fasting state or with the percent suppression of endogenous glucose production during the clamp study.

\section{DISCUSSION}

There were two novel findings in the present study. 1) An increased amount of IMCL content was found in patients with T1DM similar to what was observed in patients with T2DM and in the offspring of T2DM parents (Fig. 1, middle), and this alteration was associated with impairment of insulin sensitivity (Fig. 1, bottom). 2) Increased plasma adiponectin concentra- tions were found in insulin-resistant T1DM patients in contrast to the reduced levels found in insulin-resistant T2DM and OFF patients (Fig. 2).

Whole body insulin resistance was found to be associated with increased IMCL content in normal subjects $(25,42)$, offspring of T2DM parents $(23,35)$, individuals with HIV infection and lipodystrophy due to antiretroviral therapy $(14,27)$, and patients affected by T2DM and obesity (41). Insulin resistance is to some extent genetically inherited (38) and in the abovedescribed populations is strongly related to abdominal fat independent of total adiposity (29). In contrast, abdominal obesity, lipids, and androgens were not able to explain insulin resistance in young women with T1DM (15). The findings of this work therefore highlight the importance of IMCL content as a reliable marker of insulin resistance not only in T2DM but also in T1DM patients, as is also suggested by a previous study in which muscle triglyceride was assessed using the biopsy technique (12). In T2DM and obesity, the abnormal IMCL accretion may be determined by an unbalanced muscular fatty acid uptake, fatty acid oxidative disposal, and intramuscular lipogenic activity $(24,34)$ before the development of overt hyperglycemia. In T1DM, we found in this work a remarkable relationship between the soleus and tibialis anterior IMCL content and $\mathrm{Hb} \mathrm{A}_{1 \mathrm{c}}$ (Fig. 3). It may be speculated that, in these patients, the chronic hyperglycemic state may be relevant in the mechanisms of exaggerated IMCL accumulation. In the skeletal muscle cell, the sustained hyperglycemia (with or without high fatty acid availability) may determine a profound stimulation of acetyl-CoA carboxylase; this in turn determines a cytoplasmic accumulation of malonyl-CoA, which is a potent inhibitor of the carnitine palmitoyltransferase I system. This scenario previews a marked reduction of fatty acid transport inside the mitochondrion, a reduced fatty acid oxidative disposal, and a consequent IMCL accumulation (4), as has also been recently reported in normal healthy individuals (37) during moderately prolonged (5-h) experimental combined hyperglycemia $(8.7 \mathrm{mmol} / \mathrm{l})$ and hyperinsulinemia $(258 \mathrm{pmol} /$ 1). The T1DM patients did not undergo a more intensive insulin therapy regimen to test whether,

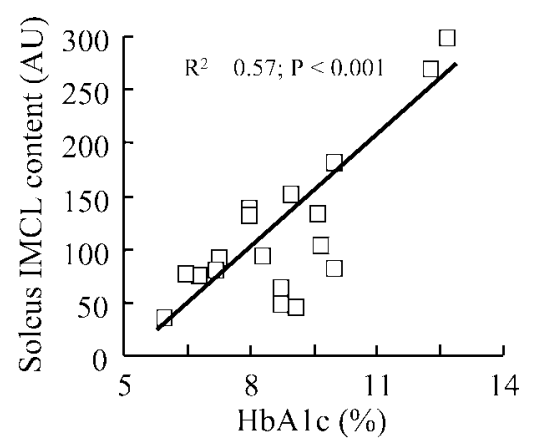

Fig. 3. Relationship between soleus IMCL content and $\mathrm{Hb} \mathrm{A}_{1 \mathrm{c}}$ in T1DM patients is depicted $\left(R^{2}=0.57, P<0.001\right)$. Also, tibialis anterior IMCL content was significantly associated with $\mathrm{Hb} \mathrm{A}_{1 \mathrm{c}}$ in T1DM patients $\left(R^{2}=0.37, P<0.02\right)$. 
along with an improvement of the metabolic control and consequent improvement of peripheral insulin sensitivity, a reduction of the IMCL content was detectable. Nevertheless, we noticed that, when analysis of data was performed segregating the T1DM patients into good $\left(n=5 ; \mathrm{Hb} \mathrm{A}_{1 \mathrm{c}}<7.5 \%\right)$ and poor $(n=13 ; \mathrm{Hb}$ $\mathrm{A}_{1 \mathrm{c}}>7.6 \%$ ) metabolic control, those in good metabolic control showed a higher insulin-stimulated glucose MCR $(P<0.05)$ in association with lower soleus IMCL content $(P<0.05$; Table 2$)$. These findings further suggest a major role of chronic hyperglycemia in the induction of abnormal IMCL accretion and development of insulin resistance in T1DM and support the possibility that, when a good glucose homeostasis is achieved, these abnormalities may, at least partially, be reversed. Whether the IMCL content was the factor able to influence directly whole body insulin sensitivity in humans has recently been challenged by data published in athletes (16) and by unpublished observations in our laboratory in patients with myotonic dystrophy. These two groups of individuals showed increased or normal insulin sensitivity in association with increased rather than decreased IMCL content. Also in this study, we observed that, when data were plotted separately by groups, muscle IMCL content was strongly associated with insulin-stimulated glucose MCR in normal-weight individuals (T1DM, OFF, and NOR), whereas the association was less pronounced in the fatter, T2DM patients. In addition, the IMCL content was similar in patients with T2DM and T1DM despite a more severe degree of insulin resistance in T2DM; this fact may be explained by the effects of other well-known variables such as the different anthropometric features of these two groups of patients (29). It must also be stated that it is now believed that the accumulation of IMCL is not the direct cause of the development of insulin resistance but rather an inert marker of the presence of other lipid intermediates (diacylglycerol, fatty acyl-CoAs, or ceramide) that have been directly linked to defects in insulin signaling (13, $18,30,39,43)$.

The second task of this work was to test whether plasma levels of adipocyte-derived peptides might be associated with the development of muscle insulin resistance, as recently suggested by several other investigators in T1DM. Measurements of fasting plasma adiponectin, leptin, and $\alpha$-TNFR2 were therefore performed in the study groups. Fasting plasma leptin and $\alpha$-TNFR2 were comparable among the normal-weight study groups. Not surprisingly, plasma leptin was increased in T2DM patients in accordance with the higher body mass index. Plasma adiponectin concentration resulted in being reduced in patients with T2DM and in the OFF compared with the NOR groups in accord with other data (20). In contrast, its plasma concentration resulted in being increased in patients with T1DM compared with the T2DM and OFF subjects but also compared with the NOR group. Apparently the plasma levels of adiponectin were not different when measured in those patients with good compared with those in poor metabolic control (Table 2).
Recently, increased plasma adiponectin concentrations were described in T1DM (22), but that report was characterized by a lack of assessment of insulin sensitivity in the study subjects. Supporting our finding of no major changes of plasma adiponectin levels depending on the metabolic control, Imagawa et al. (22) reported that intensive insulin treatment was not associated with a reduction of plasma adiponectin concentration. To our knowledge, the present work represents the first report in humans in which increased plasma adiponectin concentrations are associated with an insulin-resistant state in contrast with other classical insulin resistance conditions (T2DM and obesity), in which its level is reduced. Another condition in humans in which adiponectin showed unexpected behavior was recently reported in normal healthy individuals in whom the improvement of insulin sensitivity obtained by means of physical exercise training was not paralleled by an increment of the plasma adiponectin concentration (21). These findings therefore demonstrate that the role of adiponectin in the regulation of peripheral insulin sensitivity in vivo in humans is still unclear. Besides the relationship between adiponectin and peripheral insulin sensitivity, it is known that adiponectin has major effects at the liver site on glucose (7) and fatty acid (45) metabolism. With respect to glucose metabolism, the T1DM patients, along with increased circulating adiponectin levels, had increased fasting endogenous glucose production rates and a certain degree of resistance to the inhibitory effects of insulin, even if these parameters were not associated with the adiponectin levels and even if the insulin dose used in the present protocol was not appropriate for the assessment of hepatic insulin sensitivity. With respect to fatty acid metabolism, the intrahepatic fat content was not measured in these patients because the study was focused on peripheral insulin sensitivity. We cannot, therefore, exclude the possibility that the increased plasma adiponectin concentration found in T1DM patients may be explained by metabolic features at the liver site.

In conclusion, this work demonstrates that, in patients with T1DM, as well as in patients with T2DM and in individuals at higher risk of developing T2DM, increased IMCL content is a marker of peripheral insulin resistance, suggesting that inherited and/or acquired metabolic alterations may be predisposing factors for abnormal accretion of IMCL content and of specific IMCL intermediates able to induce insulin resistance. This study also suggests that maintenance of normal IMCL content is important for preserving insulin sensitivity, not only in patients with T2DM but also in patients with T1DM, and that recommendations for a proper lifestyle and possibly the use of drugs capable of reducing the IMCL content may represent a therapeutic tool useful to improve glucose homeostasis also in T1DM patients.

\section{DISCLOSURES}

This study was supported by grants from Telethon (JT-01) and the Juvenile Diabetes Research Foundation (JDRF) within the Telethon- 
JDRF Center for Beta Cell Replacement and by the Italian Ministry of Health (RF98.49, RF99.55, RF01.1831).

\section{REFERENCES}

1. Arita Y, Kihara S, Ouchi N, Takahashi M, Maeda K, Miyagawa J, Hotta K, Shimomura I, Nakamura T, Miyaoka K, Kuriyama H, Nishida M, Yamashita S, Okubo K, Matsubara K, Muraguchi M, Ohmoto Y, Funahashi T, and Matzusawa Y. Paradoxical decrease of an adipose specific protein, adiponectin, in obesity. Biochem Biophys Res Commun 257: 79-83, 1999

2. Baecke JAH, Burema J, and Frijters JER. A short questionnaire for the measurement of habitual physical activity in epidemiological studies. Am J Clin Nutr 36: 936-942, 1982.

3. Battezzati A, Simonson DC, Luzi L, and Matthews DE. Glucagon increases glutamine uptake without affecting glutamine release in humans. Metabolism 47: 713-723, 1998.

4. Bavenholm PN, Pigon J, Saha AK, Ruderman NB, and Efendic S. Fatty acid oxidation and the regulation of malonylCoA in human muscle. Diabetes 49: 1078-1083, 2000.

5. Berg AH, Combs TP, Du X, Brownlee M, and Scherer PE. The adipocyte secreted protein Acrp30 enhances hepatic insulin action. Nat Med 7: 947-953, 2001.

6. Boesch C, Slotboom J, Hoppeler H, and Kreis R. In vivo determination of intramyocellular lipids in human muscle by means of localized ${ }^{1} \mathrm{H}-\mathrm{MR}$-spectroscopy. Magn Reson Med 37: 484-493, 1997.

7. Combs TP, Berg AH, Obici S, Scherer PE, and Rossetti L. Endogenous glucose production is inhibited by the adipose-derived protein Acrp30. J Clin Invest 108: 1875-1881, 2001.

8. DeFronzo RA. Insulin resistance: a multifaceted syndrome responsible for NIDDM, obesity, hypertension, dyslipidaemia and atherosclerosis. Neth J Med 50: 191-197, 1997.

9. DeFronzo RA, Hendler R, and Simonson D. Insulin resistance is a prominent feature of insulin-dependent diabetes. $\mathrm{Di}$ abetes 31: 795-801, 1982.

10. DeFronzo RA, Simonson D, and Ferrannini E. Hepatic and peripheral insulin resistance: a common feature of type 2 (noninsulin-dependent) and type 1 (insulin-dependent) diabetes mellitus. Diabetologia 23: 313-319, 1982.

11. Del Prato S, Nosadini R, Tiengo A, Tessari P, Avogaro A Trevisan R, Valerio A, Muggeo M, Cobelli C, and Toffolo G. Insulin-mediated glucose disposal in type 1 diabetes: evidence for insulin resistance. J Clin Endocrinol Metab 57: 904-910, 1983.

12. Ebeling P, Essen-Gustavsson B, Tuominen JA, and Koivisto VA. Intramuscular triglyceride content is increased in IDDM. Diabetologia 41: 111-115, 1998.

13. Ellis BA, Poynten A, Lowy AJ, Furler SM, Chisholm DJ, Kraegen EW, and Cooney GJ. Long-chain acyl-CoA esters as indicators of lipid metabolism and insulin sensitivity in rat and human muscle. Am J Physiol Endocrinol Metab 279: E554E560, 2000.

14. Gan SK, Samaras K, Thompson CH, Kraegen EW, Carr A, Cooper DA, and Chisholm DJ. Altered myocellular and abdominal fat partitioning predict disturbance in insulin action in HIV protease inhibitor-related lipodystrophy. Diabetes 51: 3163-3169, 2002.

15. Greenfield JR, Samaras K, and Chisolm DJ. Insulin resistance, intra-abdominal fat, cardiovascular risk factors, and androgens in healthy young women with type 1 diabetes mellitus. J Clin Endocrinol Metab 87: 1036-1040, 2002.

16. Goodpaster BH, He J, Watkins S, and Kelley DE. Skeletal muscle lipid content and insulin resistance: evidence for a paradox in endurance-trained athletes. J Clin Endocrinol Metab 86: 5755-5761, 2001.

17. Gulli G, Ferrannini E, Stern M, Haffner S, and DeFronzo RA. The metabolic profile of NIDDM is fully established in glucose tolerant offspring of two Mexican-American NIDDM parents. Diabetes 41: 1575-1586, 1992.

18. Hajduch E, Balendran A, Batty IH, Litherland GJ, Blair AS, Downes CP, and Hundal HS. Ceramide impairs the insulin-dependent membrane recruitment of protein kinase B lead- ing to a loss in downstream signalling in L6 skeletal muscle cells. Diabetologia 44: 173-183, 2001.

19. Hother-Nielsen $\mathbf{O}$ and Beck-Nielsen $\mathbf{H}$. On the determination of basal glucose production rate in patients with type 2 (non-insulin-dependent) diabetes mellitus using primed-continuous 3- ${ }^{3} \mathrm{H}$-glucose infusion. Diabetologia 33: 603-610, 1990.

20. Hotta K, Funahashi T, Arita Y, Takahashi M, Matsuda M, Okamoto Y, Iwahashi H, Kuriyama H, Ouchi N, Maeda K, Nishida M, Kihara S, Sakai N, Nakashjima T, Hasegawa K, Muraguchi M, Ohmoto Y, Nakamura T, Yamashita S, Hanafusa T, and Matzusawa Y. Plasma concentrations of a novel, adipose-specific protein, adiponectin, in type 2 diabetic patients. Arterioscler Thromb Vasc Biol 20: 1595-1599, 2000.

21. Hulver MW, Zheng D, Tanner CJ, Houmard JA, Kraus WE, Slentz CA, Sinha MK, Pories WJ, MacDonald KG, and Dohm GL. Adiponectin is not altered with exercise training despite enhanced insulin action. Am J Physiol Endocrinol Metab 283: E861-E865, 2002.

22. Imagawa A, Funahashi T, Nakamura T, Moriwaki M, Tanaka S, Nishizawa H, Sayama K, Uno S, Iwahashi H, Yamagata K, Miyagawa J-I, and Matzusawa Y. Elevated serum concentration of adipose-derived factor, adiponectin, in patients with type 1 diabetes. Diabetes Care 25: 1665-1666, 2002.

23. Jacob S, Machann J, Rett K, Brechtel K, Volk A, Renn W, Maerker E, Matthaei S, Schick F, Claussen CD, and Häring H-U. Association of increased intramyocellular lipid content with insulin resistance in lean nondiabetic offspring of type 2 diabetic subjects. Diabetes 48: 1113-1119, 1999.

24. Kelley DE and Mandarino LJ. Fuel selection in human skeletal muscle in insulin resistance. A reexamination. Diabetes 49: 677-683, 2000.

25. Krssak M, Falk Petersen K, Dresner A, DiPietro L, Vogel SM, Rothman DL, Shulman GI, and Roden M. Intramyocellular lipid concentrations are correlated with insulin sensitivity in humans: a ${ }^{1} \mathrm{H}$ NMR spectroscopy study. Diabetologia 42: 113-116, 1999.

26. Lager I, Lönnroth P, Von Schenck H, and Smith U. Reversal of insulin resistance in type 1 diabetes after treatment with continuous subcutaneous insulin infusion. Br Med J 287: 16611664, 1983.

27. Luzi L, Perseghin G, Tambussi G, Meneghini E, Scifo P, Pagliato E, Del Maschio A, Testolin G, and Lazzarin A. Intramyocellular lipid accumulation and reduced whole body lipid oxidation in HIV-infected patients with lipodystrophy. Am J Physiol Endocrinol Metab 284: E274-E280, 2003.

28. McGarry JD. What if Minkowski had been ageusic? An alternative angle on diabetes. Science 258: 766-770, 1992.

29. Montague CT and O'Rahilly S. The perils of portliness. Causes and consequences of visceral adiposity. Diabetes 49: 883-888, 2000.

30. Montell E, Turini M, Marotta M, Roberts M, Noe V, Ciudad CJ, Mace K, and Gomez-Foix AM. DAG accumulation from saturated fatty acids desensitizes insulin stimulation of glucose uptake in muscle cells. Am J Physiol Endocrinol Metab 280: E229-E237, 2001.

31. Pedersen $\mathbf{O}$ and Beck-Nielsen $\mathbf{H}$. Insulin resistance and insulin-dependent diabetes mellitus. Diabetes Care 10: 516-529, 1987.

32. Perseghin G, Ghosh S, Gerow K, and Shulman GI. Metabolic defects in lean nondiabetic offspring of NIDDM parents. A cross-sectional study. Diabetes 46: 1001-1009, 1997.

33. Perseghin G, Mazzaferro V, Piceni Sereni L, Regalia E, Benedini S, Bazzigaluppi E, Pulvirenti A, Leão AA, Calori G, Romito R, Baratti D, and Luzi L. Contribution of reduced insulin sensitivity and secretion to the pathogenesis of hepatogenous diabetes: effect of liver transplantation. Hepatology 31: 694-703, 2000.

34. Perseghin G, Scifo P, Danna M, Battezzati A, Benedini S, Meneghini E, Del Maschio A, and Luzi L. Normal insulin sensitivity and IMCL content in overweight humans are associated with higher fasting lipid oxidation. Am J Physiol Endocrinol Metab 283: E556-E564, 2002. 
35. Perseghin G, Scifo P, De Cobelli F, Pagliato E, Battezzati A, Arcelloni C, Vanzulli A, Testolin G, Pozza G, Del Maschio A, and Luzi L. Intramyocellular triglyceride content is a determinant of in vivo insulin resistance in humans: a ${ }^{1} \mathrm{H}-{ }^{13} \mathrm{C}$ NMR spectroscopy assessment in offspring of type 2 diabetic parents. Diabetes 48: 1600-1606, 1999.

36. Perseghin G, Scifo P, Pagliato E, Battezzati A, Soldini L, Benedini S, Testolin G, Del Maschio A, and Luzi L. Gender factors affect fatty acid-induced insulin resistance in nonobese humans: effects of oral steroidal contraception. J Clin Endocrinol Metab 86: 3188-3196, 2001.

37. Rasmussen BB, Holmbäck UC, Volpi E, Morio-Liondore B, Paddon-Jones D, and Wolfe RR. Malonyl coenzyme A and the regulation of functional carnitine palmitoyltransferase- 1 activity and fat oxidation in human skeletal muscle. J Clin Invest 110: 1687-1693, 2002.

38. Samaras K, Nguyen TV, Jenkins AB, Eisman JA, Howard JM, Kelly PJ, and Campbell LV. Clustering of insulin resistance, total and central abdominal fat: same genes or same environment? Twin Res 2: 218-225, 1999.

39. Shulman GI. Cellular mechanisms of insulin resistance. J Clin Invest 106: 171-176, 2000.

40. Steele R. Influence of glucose loading and of injected insulin on hepatic glucose output. Ann NY Acad Sci 82: 420-431, 1959.

41. Stein DT, Szczepaniak L, Dobbins R, and McGarry JD. Increasing intramyocellular triglyceride stores are associated with impaired glucose tolerance and NIDDM (Abstract). Diabetes 48, Suppl 1: 287A, 1999.

42. Szczepaniak LS, Babcock EE, Schick F, Dobbins RL, Garg A, Burns DK, McGarry JD, and Stein DT. Measurement of intracellular triglyceride stores by ${ }^{1} \mathrm{H}$ spectroscopy: validation in vivo. Am J Physiol Endocrinol Metab 276: E977-E989, 1999.

43. Thompson AL and Cooney GJ. Acyl-CoA inhibition of hexokinase in rat and human skeletal muscle is a potential mechanism of lipid-induced insulin resistance. Diabetes 49: 1761-1765, 2000.

44. Weyer C, Funahashi T, Tanaka S, Hotta K, Matzusawa Y, Pratley RE, and Tataranni PA. Hypoadiponectinemia in obesity and type 2 diabetes: close association with insulin resistance and hyperinsulinemia. J Clin Endocrinol Metab 86: 1930-1935, 2001.

45. Xu A, Wang Y, Keshaw H, Xu LY, Lam KSL, and Cooper GJS. The fat-derived hormone adiponectin alleviates alcoholic and non-alcoholic fatty liver diseases in mice. J Clin Invest 112: 91-100, 2003.

46. Yamauchi T, Kamon J, Waki H, Terauchi Y, Kubota N, Hara K, Mori Y, Ide T, Murakami K, Tsuboyama-Kasaoka N, Ezaki O, Akanuma Y, Gavrilova O, Vinson C, Reitman ML, Kagechida H, Shudo K, Yoda M, Nakano Y, Tobe K, Nagai R, Rimura S, Tomita M, Froguel P, and Kadowaki T. The fat derived hormone adiponectin reverses insulin resistance associated with both lipoatrophy and obesity. Nat Med 7: 941946, 2001.

47. Yki-Järvinen $\mathbf{H}$ and Koivisto VA. Natural course of insulin resistance in type 1 diabetes. $N$ Engl J Med 315: 224-230, 1986.

48. Yu JG, Javorschi S, Hevener AL, Kruszynska YT, Norman RA, Sinha M, and Olefsky JM. The effect of thiazolidinediones on plasma adiponectin levels in normal, obese, and type 2 diabetic subjects. Diabetes 51: 2968-2974, 2002.

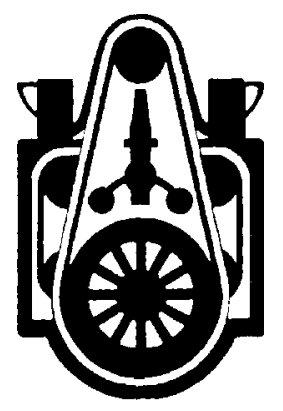

